\title{
PEMANFAATAN WHATSAPP PEMANFAATAN WHATSAPP DALAM MENINGKATKAN PEMAHAMAN ORANGTUA MENGENAI KOMUNIKASI POSITIF DENGAN ANAK
}

\author{
Najah Zulfaya \\ IKIP Siliwangi Bandung \\ najahzulfaya.pls@gmail.com
}

Received: Juli, 2020; Accepted: September, 2020

\begin{abstract}
Parents are the first to take the responsibility of raising a child with the quality of love that boils down to the quality of communication. The problem is the role of a parent, because of his misunderstanding of communication problems with his own child. So the study is aimed at figuring out how to exploit whatsapp in improving the understanding of positive communication with children. The method used is qualitative descriptive, by data collection using a trundating method of observation, interview and documentation. Informant number three. Research location in kampong gunteng, cisponsor district. The findings suggest that as intelligent parents, therefore using the whatsapp to improve its understanding of positive communication is appropriate. What a child is like from a child's communication with his parents. Positive communication, then, has a profound effect on a parent's relationship with a happy child.
\end{abstract}

Keywords: Whatsapp Utilization, Parental Understanding, Positive Communication, And Children

\begin{abstract}
Abstrak
Orang tua adalah yang pertama bertanggungjawab dalam mengasuh anak dengan kualitas cinta yang bermuara pada kualitas komunikasi. Permasalahannya adalah peran orang tua, karena ketidakpahamannya terhadap masalah komunikasi dengan anaknya sendiri. Sehingga penelitian ini bertujuan untuk mengetahui bagaimana pemanfaatan WhatsApp dalam meningkatkan pemahaman orang tua mengenai komunikasi positif dengan anak. Metode yang digunakan adalah deskriptif kualitatif, dengan pengumpulan data menggunakan metode tringulasi yaitu observasi, wawancara dan dokumentasi. Informan berjumlah 3 orang. Lokasi penelitian di kampong Gunteng, Kabupaten Cianjur. Hasil penelitian ini menunjukkan bahwa sebagai orang tua yang cerdas, maka memanfaatkan WhatsApp untuk meningkatkan pemahamannya tentang komunikasi positif adalah tepat. Seperti apa anak adalah dari hasil komunikasi anak dengan orang tuanya. Maka, komunikasi positif sangat berpengaruh pada hubungan orang tua dengan anak yang bahagia.
\end{abstract}

Kata Kunci: Pemanfaatan Whatsapp, Pemahaman Orang Tua, Komunikasi Positif, dan Anak.

How to Cite: Zulfaya, N. (2020). Pemanfaatan WhatsApp Dalam Meningkatkan Pemahaman Orang Tua Mengenai Komunikasi Positif Dengan Anak. Comm-Edu (Community Education Journal) 3 (3), 290-296.

\section{PENDAHULUAN}

Teknologi informasi dan komunikasi saat ini berkembang begitu pesat yang mempunyai pengaruh besar terhadap kehidupan manusia. Literasi Informasi dalam kehidupan ini diperlukan guna mengoptimalkan harapan di setiap permasalahan yang ada, khususnya permasalahan antara orang tua dengan anak. Menurut Darmayanti(2016:95) mengatakan, bahwa literasi informasi adalah kemampuan untuk tau kapan ada kebutuhan untuk informasi, 
untuk dapat mengidentifikasi, menemukan, mengevaluasi, dan secara efektif menggunakan informasi tersebut untuk isu atau masalah yang dihadapi.

Hasil survei perusahaan We Are Social yang bekerja sama dengan Hootsuite pada tahun 2019 menjelaskan bahwa presentase pengguna media sosial tertinggi di Indonesia adalah YouTube sebesar $88 \%$ kemudian diikuti oleh WhatsApp dengan peringkat kedua sekitar $83 \%$. Berdasarkan hasil survey ini menunjukkan bahwa WhatsApp masih marak digunakan sebagai media pesan instan untuk semua usia, jenis kelamin, individu, maupun kelompok.

WhatsApp kini mempunyai peranan membantu permasalahan di dalam masyarakat, termasuk permasalahan keluarga antara orang tua dengan anak. Setiap membicarakan tumbuh kembang anak, pasti tidak akan terlepas pada peranan orang tua dalam pengasuhannya. Untuk membangun suatu ikatan yang kokoh antara orang tua dengan anak, salah satunya dilakukan dengan mendekatkan hubungan orang tua dan anak untuk memahami pikiran dan perasaan sebagai faktor yang b..erpengaruh dalam kegiatan komunikasi posiitif. Masih ada orang tua yang belum mampu berkomunikasi positif dengan anak, maka menurunnya kualitas penyampaian informasi tanpa nilai yang positif. Ratnasari(2010:168) menyatakan, bahwa pada masanya, kalimat-kalimat positif itu akan menjadi pondasi terbangunnya suatu kehidupan yang sukses yang membahagiakan diri dan orang lain. Dengan begitu, yang paling penting dalam pengasuhan adalah meningkatkan kualitas penyampaian informasi dengan keterampilan komunikasi positif.

Komunikasi positif sangat berperan dalam menumbuhkan rasa saling menyayangi dan mengasihi antara orang tua dan anak. Dengan memanfaatkan WhatsApp pada orang tua, secara cerdas dapat menghidupkan komunikasi positif di dalam keluarga.

\section{Pendidikan Luar Sekolah}

Kartika(2015:56) mengatakan, bahwa pendidikan luar sekolah harus dikembangkan berdasarkan kebutuhan masyarakat yang ada ditengah berbagai tantangan yang ada, dengan demikian mampu memperluas akses masyarakat terhadap peningkatan kualitas kehidupan yang lebih baik.

Dalam hal ini pendidikan luar sekolah memberikan jawaban dari persoalan kehidupan yang kompleks, karna pendidikan formal tidak mampu memenuhi kebututuhan pendidikan di luar pendidikan formal.

\section{Literasi Informasi}

Garner(2005) menyatakan, bahwadalam diskusi IFLA, UNESCO dan National Forum for Information Literacy (NFIL), definisi literasi informasi, ialah:

Information literacy encompasses knowledge of one's information concerns and needs, and the ability to identify, locate, evaluate, organize, and effectively create, use and communicate information to address issues or problems at hand; it is a prerequisite for participating effectively in the Information Society,and is part of the basic human right of life - long learning

Artinya adalah literasi informa mencakup pengetahuan tentang kebutuhan dan informasi seseorang, serta kemampuan untuk mengidentifikasi, mencari, mengevaluasi, mengorganisasi, dan menciptakan, menggunakan dan mengkomunikasikan informasi untuk mengatasi masalah atau masalah yang ada; Hal itu merupakan syarat mutlak untuk berpartisipasi secara efektif dalam masyarakat informasi, dan merupakan bagian dari hak asasi manusia untuk belajar sepanjang hidup. 
Menurut Senova (2016:145) literasi informasi sebagai bentuk kajian ilmu informasi dan perpustakaan yang memiliki fokus kepada kemampuan individu atau kelompok untuk mencari atau memperoleh, mengevaluasi dan menggunkan informasi tersebut untuk kebutuhan atau pemecahan masalah baik dalam skala kecil (pribadi) atau skala besar (masyarakat).

\section{Pola Asuh}

Pola asuh adalah bentuk-bentuk yang diterapkan dalam rangka merawat, memelihara, membimbing, dan melatih dan memberikan pengaruh. (Tarmuji, 2000 dalam Apriastuti, 2013). Orang tua adalah merupakan pertama-tama yang bertanggung jawab dalam mengatur, mengkoordinasikan serta memberikan rangsangan-rangsangan (Suherman, 2000 dalam Apriastuti, 2013).

Menurut Apriastuti(2013:3) pola asuh terbagi menjadi tiga perbedaan diantaranya, pola asuh otoriter yang bersifat lebih memaksa anak, liberal yang bersifat lebih memberi kebebasan anak, dan demokratis yag bersifat lebih memperhatikan kebutuhan anak sesuai kemampuannya.

\section{Komunikasi Positif}

Komunikasi positif merupakan pesan komunikasi yang kita sampaikan mengandung energy, yaitu energy rendah dan tinggi. Pesan berenergi rendah biasanya berkaitan dengan emosi negative, sedangkan pesan berenergi tinggi memiliki daya yang kuat sehingga menggetarkan perasaan positif kita (Oswald, 2009:19 dalam Ratnasari, 2010:158).

Menurut Ratnasari (2010:168) aplikasi pesan positif diterapkan dalam beberapa bidang kehidupan perlu ditumbuhkan komitmen untuk membuat kalimat positif sebagai satu sikap hidup yang apabila dilatih lambat laun akan menjadi kebiasaan positif dalam menghasilkan komunikasi yang positif.

\section{METODE}

Metode penelitian yang digunakan dalam penelitian ini adalah metode deskriptif kualitatif. Penelitian ini pada dasarnya tidak mengutamakan besarnya sampling. Heryana (2019:142) mengatakan, bahwa dalam penelitian kualitatif, informan terbagi menjadi tiga, yaitu : 1 . Informan kunci; 2. Informan utama; dan 3. Informan pendukung. Maka subjek penelitian yang bisa memberikan informasi disini berjumlah 3 orang yaitu: seorang Ibu sebagai informan kunci, seorang anak laki-laki sebagai informan utama, dan seorang temanperempuan sebagai informan pendukung.

Menurut Wahyuni (2014), bahwa dalam wawancara-mendalam melakukan penggalian secara mendalam terhadap satu topik yang telah ditentukan (berdasarkan tujuan dan maksud diadakan wawancara tersebut) dengan menggunakan pertanyaan terbuka. Penggalian yang dilakukan untuk mengetahui pendapat mereka berdasarkan perspective responden dalam memandang sebuah permasalahan. Teknik wawancara ini dilakukan oleh seorang pewawancara dengan mewawancarai satu orang secara tatap muka (face to face).

Maka, penelitian ini melakukan wawancara yang mendalam di Kampung Gunteng, Kabupaten Cianjur. Pertama, wawancara yang mendalam dilakukan pada 1 orang (orang tua, perempuan) guna mendapatkan informasi yang berhubungan dengan latar belakang dan tujuan pemanfaatan WhatsApp dalam meningkatkan pemahaman orang tua mengenai komunikasi positif. Kedua, wawancara yang mendalam dilakukan pada 1 orang (anak, laki-laki) guna mendapatkan informasi mengenai bagaimana anak laki-laki berkomunikasi dengan orang tuanya. Dan ketiga, 
wawancara yang mendalam dilakukan pada 1 orang (teman anak, perempuan) guna mendapatkan informasi mengenai bagaimana pendapatnya mengenai anak laki-laki tersebut. Peneliti menggunakan cara teknik sampling purposive dalam melakukan analisis informan. Teknik ini merupakan teknik sampling yang satuan samplingnya memiliki karakteristik atau kriteria yang dikehendaki dan diseleksi berdasarkan tujuan peneliti. Data yang dikumpulkan adalah data primer dan data sekunder. Peneliti mengumpulkan data primer melalui observasi dan wawancara, serta data sekunder melalui dokumentasi. Yang kemudian sumber data yang dikumpulkan secara langsung dan juga tidak langsung dari sumber data sesuai dengan kebutuhan proses penelitian.

Peneliti melakukan observasi secara langsung di lokasi penelitian dengan mengamati subjek yang teliti secara terbuka. Kemudian peneliti memusatkan perhatian dengan memperhatikan analisa secara interkasi yang komunikatif sesuai aktivitassubjekyang diteliti. Disini, peneliti menganalisis berbagai dokumen dimulai dari screenshoot percakapan dalam pemanfaatan WhatsApp dan juga recorder wawancara mendalam dengan responden. Peneliti berfokus pada pengalaman-pengalaman responden dengan cara berinteraksi antara peneliti dengan subjek yang diteliti untuk menumpulkan data.

Metode yang digunakan pada prosedur pengumpulan data dalam penelitian ini adalah Triangulasi. Triangulasi adalah suatu pendekatan analisa data yang mensistesa data dari berbagai sumber. Triangulasi adalah teknik pemeriksaan keabsahan data dengan cara memanfaatkan sesuatu yang lain di luar data itu sendiri, untuk keperluan pengecekan atau sebagai pembanding terhadap data itu (Bachri, 2010:56).

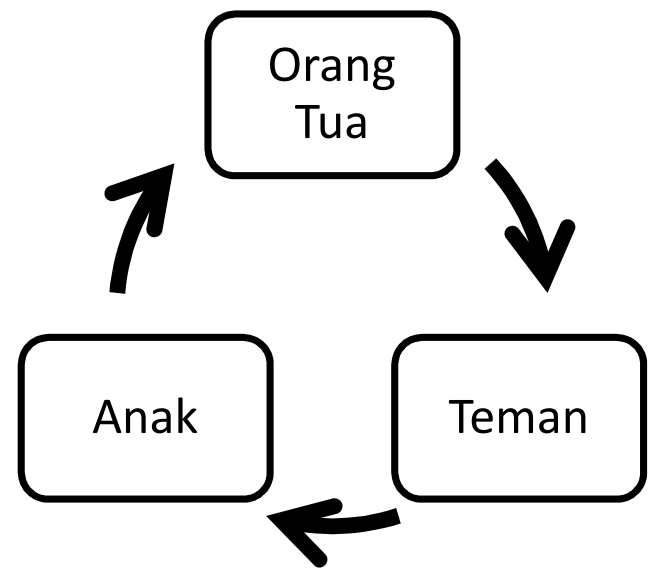

Gambar 1. Sumber Triangulasi Data Penelitian

\section{HASIL DAN PEMBAHASAN}

Hasil

Dari hasil wawancara yang dilakukan, menunjukkan bahwa WhatsApp bermanfaat dalam meningkatkan pemahaman ornag tua mengenai komunikasi positif.

"Baru setahunan, banyak manfaatnya. Jadi saya bisa ngasih tahu kakaknya, anak saya yang besar. Ibu keadaannya sekarang gini, sekarang adik-adiknya keadaannya gini.Alhamdulillah anak saya suka ngasih nasihat gimana ke Ibu, supaya Ibu sabar, 
supaya Ibu lebih menghadapi anak-anak lebih sabar, jangan terlalu keras."(orang tua, $\mathrm{Ibu})$

Selain informasi yang didapatkan melalui wawancara, peneliti juga mendapatkan informasi melaui dokumentasi sebagai hasil penelitian bahwa orang memanfaatkan WhatsApp dalam obrolan pembelajaran mengenai pengasuhan positif.

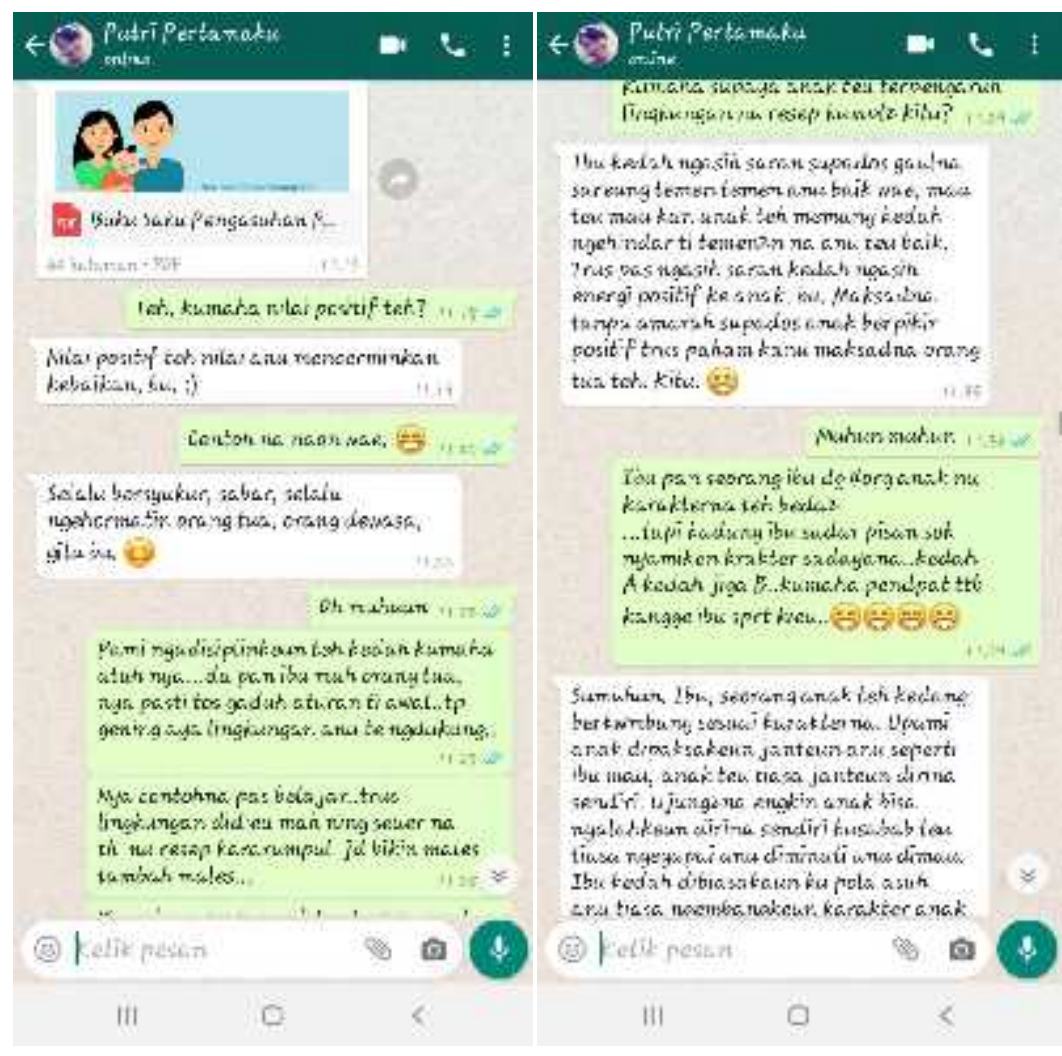

Gambar 2. Informasi Mengenai Buku Saku Pengasuhan Positif

"Ibu lebih keras ke anak-anak, tapi Alhamdulillah anak saya yang udah besar, Alhamdulillah mengerti, ngenasehatin. Ibu lebih bisa mengeluarkan unek-unek ke anakanak, masalahnya jadi lebih cepat selesai."'(orang tua, Ibu)

Berhubungan dengan hal tersebut, sebagai orang tua sebaiknya tidak terlalu keras terhadap seorang anak.

"Jadi memberi tahu kepada saya, mengingatkan saya. Memberi tahu saya secara langsung, berbicara. Sekarang belajar, atau sekarang nih perdalami ini. Jadi, langsung kepada saya. Kadang juga kalau di luar, di sekolah juga. kadang mengingatkan kepada saya, nih harus belajar nih, naikin nilai yang ini, yang ini yang itu. Perasaan saya sebagai anak yang mungkin sedikit terkekang, terganggu. Jika terus saya dituntut seperti itu, sikap orang tua saya itu agak terbilang kasar, sedikit kasar, sering berbicara dengan nada tinggi. Sering menuntut ini-itu, terbilang sering. Dan orang tua saya terbilang over protective terhadap saya terutama Ibu saya."(laki-laki, anak)

"Kalau tentang keluarga biasanya paling bicarain kalau misalnya pulang telat dari sekolah. Nyeritain mamahnya, biasanya gitu. Harus nelepon mamah dulu nih, biar gak kena marah atau gimana. Cerita kalau pulang telat nanti dia bakal di marahin, kalau enggak ada kabr terlebih dahulu. Kadang-kadang, rebut langsung buka HP kaya gitu, langsung ngabarin.”(perempuan, teman anak laki-laki) 
Rasa terkekang, dan terganggu pada anak membuat ketidak efektifan dalam berkomunikasi antara orang tua dengan anak. Anak menjadi tidak begitu terbuka terhadap orang tua, dan menjadi seorang anak yang pendiam.

"Kritis orangnya, di organisasi aktif. Lebih aktif, enggak seperti keliatan yang di rumah, diem. Banyak berkomunikasi sama temen-temen yang lain juga, seneng bercanda. Dafa terbuka, kadang suka menceritakan hal-hal pribadi., keluarga kadangkadan." (perempuan, teman anak laki-laki)

\section{Pembahasan}

Yusmita, Larisu, dan Saidin(2018:11) mengatakan WhatsAppsangat bermanfaat dan membantu dalam proses berkomunikasi, memberi dan menerima informasi. WhatsApp sangat popular digunakan yang sangat potensial untuk dimanfaatkan sebagai alat penyampaian informasi yang berisi pembelajaran yang dapat diakses secara individu ke individu dengan mudah. Dengan begitu, WhatsApp merupakan media literasi untuk menyampaikan dan mendapatkan informasi secara efektif.

Sebagai orang tua yang cerdas, maka memanfaatkan WhatsApp untuk meningkatkan pemahamannya tentang komunikasi positif adalah tepat. Komunikasi positif menurut Ratnasari (2010:168) merupakan kalimat-kalimat positif itu akan menjadi fondasi terbangunnya suatu kehidupan yang sukses yang membahagiakan diri dan orang lain. Hal yang terkait pemanfaatan dalam penelitian ini karena adanya informan yang menyatakan bahwa ia sudah menggunakan whatsapp cukup lama. Dan WhatsApp digunakannya untuk berbagi dan berdiskusi dengan keluarga terkait permasalahan anak di rumah. Ia menyadari bahwa ia mempunyai pola asuh yang sangat keras terhadap anak. Yang kemudian ia memanfaatkan WhatsApp untuk mendapatkan pemahaman terkait pengasuhan positif, khususnya komunikasi positif dengan anak-anaknya.

Membicarakan anak tidak jauh dengan bagaimana orangtua mengasuhnya. Sehingga orang tua mempunyai peranan sangat penting dan utama dalam mengasuh anak. Hal ini dikarnakan adanya informan yang menyatakan bahwa ia merasa terkekang dengan pola asuh orang tuanya yang keras, berbicara dengan nada tinggi, kurang rasa empati pada prestasi anak, namunover protective. Dampaknya membuat ia menjadi anak yang sangat pendiam dan tertutup di rumah, tetapi ia sangat aktif ketika berada diluar atau di sekolah bersama teman-temannya.

Hal itu pun dibenarkan oleh salah seorang informan lagi yang menyatakan bahwa ia berteman dengannya sudah sangat lama. Dalam jalinan pertemanannya pun terbiasa berkomunikasi dengan anak tersebut secara terbuka, senang bergurau, dan sangat aktif.

\section{KESIMPULAN}

WhatsApp sangat bermanfaat bagi penggunanya untuk menyampaikan dan mendapatkan informasi. Sebagai orang tua yang mempunyai permasalahan dalam pola asuh memang tidak bisa hanya sekedar menggunakan WhatsApp namun juga harus dimanfaatkan untuk menambah pengetahuan dan pemahamannya tentang pola asuh. Pola asuh yang baik diantaranya mampu berkomunikasi yang positif dengan anak. Seperti apa anak adalah dari hasil komunikasi anak dengan orang tuanya. Maka, komunikasi positif sangat berpengaruh pada hubungan orang tua dengan anak yang bahagia. 
296 Zulfaya, Pemanfaatan WhatsApp Dalam Meningkatkan Pemahaman Orang Tua Mengenai Komunikasi Positif Dengan Anak

\section{DAFTAR PUSTAKA}

Senova, A. (2016).Literasi Media Sebagai Strategi Komunikasi Tim Sukses Relawan Pemenangan Pemilihan Presiden Jokowi JK Di Bandung. Jurnal Kajian Komunikasi, Volume 4 No.2, hal. 142-153

Ratnasari, A. (2010).Pesan Positif dalam Komunikasi.Mimbar, Volume XXVI No. 2, hal.159168

Apriastuti, D.A. (2013). Analisis Tingkat Pendidikan Dan Pola Asuh Orang Tua Dengan Perkembangan Anak Usia 48-60 Bulan. Junal Ilmiah Kebidanan, Volume 4 No. 1, hal. 114

Yusmita, M. Larisu, Z, dan Saidin.(2018). Pemanfaatan WhatsApp Messenger Sebagai Media Komunikasi Antar Pribadi Mahasiswa Ilmu Komunikasi.Open Jurnal System Halu Oleo University, Volume 3 No.4, hal. 1-12

Darmayanti, R. (2016). Membangun Budaya Literasi Informasi Bagi Masyarakat Kampus. Jurnal Iqra', Volume 10 No.1, hal.92-101

Heryana, A. (2019). Buku Ajar Metodelogi Penelitian Pada Kesehatan Masyarakat.Jakarta: ebook tidak dipublikasikan

Kartika, P. (2015). Optimalisasi Peran Masyarakat Dalam Pemberdayaan Masyarakat Melalui Pendidikan Luar Sekolah. Jurnal Empowerment, Volume 3 No. 1, hal. 50-57

Garner, S.D.(2005). High-Level Colloquium on Information Literacy and Lifelong Learning. Egypt: Bibliotecha Alexandrina

Bachri, B.S. (2010). Meyakinkan Validitas Data Melalui Triangulasi Pada Penelitian Kualitatif.Jurnal Teknologi Pendidikan, Volume 10 No. 1, hal. 46-62 